\title{
EDITORIALS
}

\section{Talk is cheap}

\author{
Richard W Casey MD FRCSC ${ }^{1}$, Editor-in-Chief
}

\begin{abstract}
A assisted reproductive techniques have improved, I have found that the role of the Urologist has diminished in the treatment of infertile couples. The pressures of reproduction cause significant disturbances in these couples and many would benefit from counseling. A successful treatment program should include onsite nurse educators
\end{abstract}

or counselors to support couples through these stressful investigations and procedures. This will increase the costs to prospective parents, but as a father of four can attest to, even in vitro fertilization is cheap compared with the expenditures for the next 18 years.

\section{Male infertility: Is there hope?}

\author{
Serge Carrier MD FRCSC ${ }^{2}$, Guest Editor
}

\begin{abstract}
$A \mathrm{~s}$ we saw in the previous issue of the Journal of Sexual $\mathcal{E}$
A Reproductive Medicine, the management and evaluation of the infertile couple have undergone tremendous changes since the first successful in vitro fertilization (IVF) pregnancy 24 years ago. IVF techniques have improved and become more reliable, and these new techniques now allow us to either use a single sperm from the ejaculate semen or to harvest a single sperm directly from the genital tract to
\end{abstract}

inseminate the ovula (ICSI). These techniques give men, for whom it was impossible 10 years ago to induce a pregnancy, the opportunity to have children of their own. This second issue of the Journal that focuses on infertility will allow the reader to better understand the difficulties that a couple who is dealing with infertility has to go through and the importance of the decisions that the couple has to make in order to have a child.

\footnotetext{
${ }^{1}$ The Male Health Centres, Oakville, Ontario; ${ }^{2}$ Department of Surgery, Division of Urology, McGill University Health Centre, Royal Victoria Hospital, Montreal, Quebec

Correspondence: Dr Richard W Casey, 407-1235 Trafalgar Road North, Oakville, Ontario L6H 3P1. Telephone 905-338-3130, fax 905-338-3150, e-mail drcasey@malehealth.com; Dr Serge Carrier, 687 Pine Avenue West, Royal Victoria Hospital S6.92, Montreal, Quebec H3A 1A1. Telephone 514-842-1231 ext 34302, fax 514-843-1552, e-mail serge.carrier@mcgill.ca
} 